\title{
Territorialidades en la ciudad-región Eje Cafetero, Colombia
}

Territory, Territorialization, Appropriation, Identity, City-Region

Territorialidades na cidade região eixo Cafeeiro, Colômbia

\section{Mario Alberto Gaviria Ríos*}

Recibido: 27 de julio de 2018

Aprobado: 30 de julio de 2019

Doi: https://www.doi.org/10.12804/revistas.urosario.edu.co/territorios/a.7012

Para citar este artículo:

Gaviria Ríos, M. A. (2020). Territorialidades en la ciudad-región Eje Cafetero, Colombia. Territorios, (42), 1-24. Doi: https://www.doi.org/10.12804/revistas.urosario.edu.co/territorios/a.7012

* Profesor en la Universidad Católica de Pereira. Correo electrónico: mario. gaviria@ucp.edu.co. ORCID: https://orcid. org/0000-0002-8495-4260 
Palabras clave

Territorio,

territorialización, apropiación, identidad, ciudad-región.

Keywords

Territory, territorialization, appropriation, identity, city region.

Palavras-chave

Território, territorialização, apropriação, identidade, cidade região.

tersitarias 42

\section{RESUMEN}

En este trabajo se exploran las territorialidades que hacen presencia en la ciudad-región Eje Cafetero, sistema urbano localizado en el centro occidente colombiano. Estas territorialidades se expresan en las relaciones de apropiación e identidad que manifiestan sus habitantes con dicha forma espacial. Por medio de la entrevista semiestructurada aplicada a actores sociales se evidenció la existencia de una pertenencia territorial anclada en el pasado (colonización, cultura cafetera), pero que se renueva con los fenómenos actuales y se redefine a partir de estos. La ciudad-región como territorio para el desarrollo cobra importancia en el discurso de los actores.

\section{ABSTRACT}

This paper explores the territorialities present in the Eje Cafetero's city region, an urban system located in Colombia's center-west expressed in the relations of appropriation and identity manifested by its inhabitants. Through the semi-structured interview applied to social actors, the existence of a territorial belonging anchored in the past (colonization, coffee culture) was evidenced, but it is renewed with the current phenomena and redefined from them: the city region as a territory for development acquires importance in the discourse of the actors.

\section{RESUMO}

Neste trabalho exploram-se as territorialidades que fazem presença na Cidade região Eixo Cafeeiro, sistema urbano localizado no centro-ocidente colombiano, as quais se expressam nas relações de apropriação e identidade que manifestam seus habitantes com dita forma espacial. Através da entrevista semiestruturada aplicada a atores sociais se evidenciou a existência de uma pertença territorial ancorada no passado (colonização, cultura cafeeira), mas que se renova com os fenômenos atuais e redefine-se a partir dos mesmos; que a cidade região como território para o desenvolvimento toma importância no discurso dos atores. 


\section{Introducción}

Los procesos derivados de la globalización, los desarrollos en las tecnologías del transporte y las comunicaciones y los cambios sociales han tenido efectos importantes en la organización espacial de las ciudades y han favorecido un proceso de expansión urbana en su ámbito regional. Esto se expresa en nuevos sistemas de ciudades en los que es posible observar una intensificación de las relaciones entre las unidades urbanas principales, sus periferias rurales, las ciudades pequeñas, las mismas que se constituyen en núcleos emergentes que abastecen de mano de obra y proveen otros servicios a la ciudad central (Indovina, 2004; Monclús, 1998; Dematteis, 1998, Soja, 2008).

La presencia de estos fenómenos y la forma espacial derivada ha dado lugar a la aparición de diversas expresiones que intentan describirla, entre las que se destaca la 'ciudad-región', término que hace referencia de manera especial a los diversos rasgos que marcan diferencias sustanciales de la nueva forma espacial con aquella que había caracterizado a la ciudad compacta tradicional. Las definiciones de la ciudadregión han tendido a centrarse en los vínculos funcionales entre las ciudades y sus alrededores, acá es definida como un sistema de ciudades en el que confluyen unidades de diverso tamaño, que toma forma fundamentalmente a partir de una dinámica relacional sustentada en un flujo sostenido de interacciones socioeconómicas claramente favorecidas por la proximidad geográfica existente.

En el centro occidente de Colombia se ha evidenciado la configuración de un sistema de ciudades nombrado como ciudad-región Eje Cafetero, que integra 15 municipios de los departamentos de Caldas, Quindío, Risaralda y Valle del Cauca, y se forma de conglomerados urbanos derivados de procesos de metropolización observados alrededor de las capitales de los tres primeros departamentos (Manizales, Armenia, Pereira), los cuales se articulan a lo largo del corredor regional que se consolida con la Autopista del Café (Corporación Alma Mater, Carder, Corpocaldas, Cortolima, CRQ, CVC, Ministerio del medio ambiente, 2002). En ese sentido, además de las capitales anteriores, los municipios identificados son Chinchiná, Villamaría, Palestina, Neira, Cartago, La Virginia, Dosquebradas, Santa Rosa de Cabal, Calarcá, Circasia, La Tebaida y Montenegro.

En esta forma espacial se percibe la presencia de interacciones socioeconómicas de diverso orden entre los habitantes de las unidades integrantes, que se fundamentan en gran medida en las proximidades geográficas, culturales e históricas existentes y a partir de las cuales se evidencia la configuración de una red de ciudades. Una red en la cual las ciudades, si bien conservan su autonomía territarios 42 
1 Nates (2011) advierte que el hecho de que el territorio, al contrario del espacio físico, sea una significación cultural con variadas implicaciones a nivel social, ha llevado a que se convierta en objeto de estudio de distintas disciplinas.

\section{territarias 42}

como entidades territoriales, se hacen crecientemente interdependientes en su desempeño (Gaviria, 2018).

Teniendo presente que desde el enfoque de redes de ciudades se destaca como elemento constitutivo de un territorio la matriz de relaciones socioeconómicas que se configura a partir de las interacciones de los habitantes de esas ciudades, que esas redes se conciben como un dispositivo capaz de producir territorio - más a partir de las relaciones que de la ocupación (Monnet, 1999, 2013; Raffestin, 2011)el propósito de este trabajo es explorar las territorialidades que hacen presencia en la ciudad-región Eje Cafetero, expresadas a través de las relaciones de apropiación e identidad que manifiestan sus habitantes con dicha formación espacial.

Para ello, se acudió a la técnica cualitativa de la entrevista semiestructurada, asumida como una manera de acercarse a la experiencia cotidiana de las personas en diferentes tiempos y lugares. Se aplicó a 26 actores sociales de la ciudad-región, entendidos como unidades de decisiónacción responsable (García, 2007) que están motivados por intereses particulares, a la vez que son conscientes de la importancia de tener una visión colectiva sobre su territorio, e identificados desde su esfera de actuación.

Sumado a esta introducción, el informe contiene otras tres partes. En la primera se delimita el campo problemático del territorio como concepto central para la investigación; en la segunda se identifican los elementos de territorialidad que hacen presencia en la ciudad-región Eje Cafetero, con fundamento en la entrevista a actores sociales y en la tercera se plantean algunas reflexiones a modo de conclusión.

\section{La polisemia del concepto territorio}

El concepto de 'territorio' ha tenido un uso académico desde la Geografía y otras disciplinas, ${ }^{1}$ principalmente la antropología y la ciencia política, avanzando en esfuerzos de investigación y reflexión teórica de carácter interdisciplinar. Entre las concepciones, es mayoritaria la jurídicopolítica, en gran medida como derivación de la tradición iniciada por el geógrafo alemán Friedrich Ratzel, que consideró a los Estados como organismos que deben ser concebidos en íntima conexión con el espacio, con lo cual enfatizó en la importancia del suelo como condición necesaria para su realización. Sus planteamientos estuvieron apoyados en una visión determinista que concibe el comportamiento territorial de los seres humanos como algo natural asociado con la necesidad innata de un espacio (Storey, 2012).

En contraposición al determinismo geográfico de Ratzel, y sus consecuencias expansionistas y colonialistas, con la influencia de Paul Vidal de La Blache, la geografía privilegió desde finales del siglo XIX los conceptos de paisaje y región (Schneider \& Peyré, 2006; Saquet, 2007; Vargas, 2012). Fue solo hasta los años 
setenta del siglo XX que se retomó la discusión alrededor del concepto de territorio, pero conservándose la línea impuesta por Ratzel, la del territorio estatal. Como se describe de manera amplia en Storey (2012), Jean Gottmann destacó que el territorio es una expresión de poder, representado en una porción de espacio geográfico bajo la jurisdicción de un grupo de personas, definido por límites (líneas) y con un sistema de leyes y una unidad de gobierno; por su parte Robert Sack enfatizó en el control del acceso a un cierto espacio como definidor del territorio.

La línea del territorio estatal se rompe con el geógrafo francés Claude Raffestin (2011), que en su texto Por una geografía del poder, publicado originalmente en francés en 1980, cuestiona lo que denomina una 'geografía unidimensional' en la que el territorio es definido exclusivamente en relación con el poder en la escala estatal. Como alternativa analítica defiende la existencia de múltiples poderes que se manifiestan en las estrategias regionales y locales, considerando así que las relaciones de poder se originan en incontables puntos y contienen variadas intencionalidades.

De esa manera, desde la geografía política, el concepto de territorio remite casi siempre a relaciones de poder, ya sea al nivel del Estado o al de las comunidades locales. Pero el territorio no se reduce a una dimensión política, las razones y motivaciones para conquistarlo o defenderlo también son de orden cultural, económica o ambiental. Por ello, como lo argumentan
Capel (2016), Haesbaert (2011, 2013), Lopes Souza (2009) y Farias, Saquet y Alves (2005), desde otras áreas de las ciencias sociales se han enfatizado diversos elementos para la comprensión del territorio, como la economía que desde la noción de región lo percibe como un factor locacional o fuente de recursos; la biología y la ecología, que lo conciben como espacio de vida; la sociología, que se enfoca en las relaciones sociales; la antropología, que destaca su dimensión simbólica; y la psicología que lo vincula con la identidad personal.

Con fundamento en lo anterior, se puede afirmar que, para entender el territorio, resulta esencial asumirlo como un fenómeno geo-socio-histórico de carácter multidimensional, ${ }^{2}$ articulación esta que se concreta por medio de la apropiación social del espacio y las formas de relación que con él establecen los seres humanos. Dinámicas de apropiación en las cuales se pueden combinar los usos utilitarios y la valoración simbólica, apreciación que llega a soportar en parte las identidades individuales y colectivas. Es en ese sentido, el territorio se entiende como un espacio construido socialmente, en el transcurrir histórico y mediante procesos de orden político, cultural y económico, un espacio social en los términos de Milton Santos (1994, 2000).

$\mathrm{Si}$ bien es preciso admitir que el territorio posee un substrato material, él es también una figura inmaterial cargada de simbología y sentimientos de apego
${ }^{2}$ Multidimensionalidad entendida en el sentido que lo plantea Nates (2011), en tanto el territorio participa de tres órdenes distintos: de la materialidad de la realidad concreta, considerando la realidad geográfica; de la psiquis individual, desde la que el ser humano establece una relación emocional con la tierra; $y$ de las representaciones colectivas, sociales y culturales.

territarias 42 
y pertenencia por el espacio apropiado, la cual acaba constituyéndose en uno de los atributos fundamentales de sus habitantes. De esa manera, se puede entender que los territorios sigan siendo soportes privilegiados de la actividad simbólica y lugares de inscripción de las 'excepciones culturales', pese a la presión homologante de la globalización, como bien afirma Giménez (1999).

El concepto de territorio está vinculado con su etimología, territorium, que hace referencia a la posesión de una superficie terrestre, pero igual está dotado de un bagaje cultural; por lo que él refiere tanto al poder en el sentido más concreto, de dominación, como en su significado más simbólico, de apropiación. La apropiación del territorio por un grupo social es un proceso generador de raíces e identidad entre los individuos que lo integran, de modo tal que el grupo ya no puede ser comprendido en su plenitud sin su territorio, que constituye base de su historia, cultura y sustentación.

A partir de esta discusión, es posible avanzar en la delimitación del campo problemático del territorio, considerando como dimensiones estratégicas del mismo el poder las relaciones sociales, la funcionalidad y las representaciones simbólicas del territorio (tabla 1). Queda en ello plasmada la idea de que el territorio es un concepto de orden político, cultural, social, económico y ambiental; que, si bien posee un substrato material, el espa-

\section{territarios 42}

cio que le sirve de soporte es también y principalmente esa dimensión intangible del espacio social.

Tabla 1. Campo problemático del territorio

\begin{tabular}{|l|l|l|}
\hline $\begin{array}{l}\text { Dimensión } \\
\text { estratégica }\end{array}$ & Intereses relevantes & $\begin{array}{c}\text { Aspecto } \\
\text { dominante }\end{array}$ \\
\hline Poder & $\begin{array}{l}\text { Control, delimitación, } \\
\text { transformación. }\end{array}$ & Político \\
\hline $\begin{array}{l}\text { Soporte } \\
\text { físico }\end{array}$ & $\begin{array}{l}\text { Localización, pro- } \\
\text { ducción, distribu- } \\
\text { ción, consumo. }\end{array}$ & Económico \\
\hline $\begin{array}{l}\text { Espacio } \\
\text { de vida }\end{array}$ & $\begin{array}{l}\text { Sustentabilidad, } \\
\text { reproducción. }\end{array}$ & Ambiental \\
\hline Relacional & $\begin{array}{l}\text { Reproducción social } \\
\text { y económica. }\end{array}$ & $\begin{array}{l}\text { Económico/ } \\
\text { social }\end{array}$ \\
\hline $\begin{array}{l}\text { Representa- } \\
\text { ciones }\end{array}$ & $\begin{array}{l}\text { Identidad, } \\
\text { reproducción social. }\end{array}$ & Cultural \\
\hline
\end{tabular}

Fuente: elaboración propia con base en Cuervo (2006).

\section{Territorialidad como identidad territorial}

La territorialidad se entiende como el conjunto de relaciones establecidas entre los seres humanos integrantes de una sociedad y su exterioridad o alteridad (Raffestin, 2011), es decir, el sistema de valores que estos conceden al espacio geográfico ocupado, en un proceso esencialmente simbólico que asocia apropiación e identidad. La territorialidad corresponde a los valores asignados a un espacio, en un sentido de pertenencia e identidad territorial (Monnet, 2013).

Blanco, Wulff y Basualdo (2014), al igual que Molina (2011), destacan que 
desde tradiciones filosóficas, como la aristotélica, la idea de identidad fue asociada con las representaciones de los rasgos característicos de los seres humanos; es decir, que era concebida como atributo de la personalidad, considerándose así que ella poseía un carácter subjetivo que venía desde adentro. De ese modo, por largo tiempo la reflexión filosófica redujo el fenómeno de la identidad a un sentimiento de mismidad individual/personal, no aplicable al estudio de las identidades sociales.

Sin embargo, las filosofías modernas comienzan a destacar la reflexividad como elemento crucial en la construcción de la identidad humana. Asimismo, al interior de las ciencias sociales y humanas contemporáneas comienza a observarse un giro en la comprensión de los procesos de construcción de identidad, llegando a entender que una primera etapa en la formación de identidad personal se alcanza cuando un individuo aprende a concebirse también desde el exterior, es decir, desde la perspectiva del 'otro'.

Desde esta postura es decisivo entender que la identidad se construye de forma relacional y no substancial, es decir, siempre en el encuentro con los otros; por lo que se concibe como un fenómeno que surge de la dialéctica entre el individuo y la sociedad (Blanco, et al., 2014; Molina, 2011). De ese modo, la identidad es un proceso de construcción histórico-social; por lo mismo, si bien es estable y muestra capacidad de perdurar en el tiempo y en el espacio, ella no es estática.

Giménez (1999) y Blanco et al. (2014) coinciden en destacar que la dimensión espacial es igualmente clave en la formación de las identidades, que la relación con el espacio geográfico es un componente que facilita o consolida dicha construcción. Se entiende entonces que la identidad territorial se deriva de un sentido de pertenencia socio-territorial que se da cuando una parte significativa de un grupo humano se siente profunda y emocionalmente vinculado al espacio que habita, a su historia, tradiciones, paisajes y expresiones culturales que le dan singularidad (figura 1).

Por consiguiente, la identidad territorial implica un compromiso vital de las personas con el pasado, presente y futuro de los procesos económico-sociales y culturales que se desarrollan en su espacio (Giménez, 1994, 1999; Amtmann, 1997). El mismo Giménez (2005) advierte que esa identidad territorial se constituye en una parte del autoconcepto de las personas y la imagen distintiva y específica que se forjan de sí mismas en el proceso de sus relaciones con otras regiones y colectividades. Imagen que puede ser más o menos compleja y tener por fundamento ya sea un patrimonio pasado o presente, o un entorno natural valorizado, o una historia, o una actividad económica específica, o, finalmente, una combinación de todos estos factores. 
Figura 1. Concepciones de identidad e identidad territorial

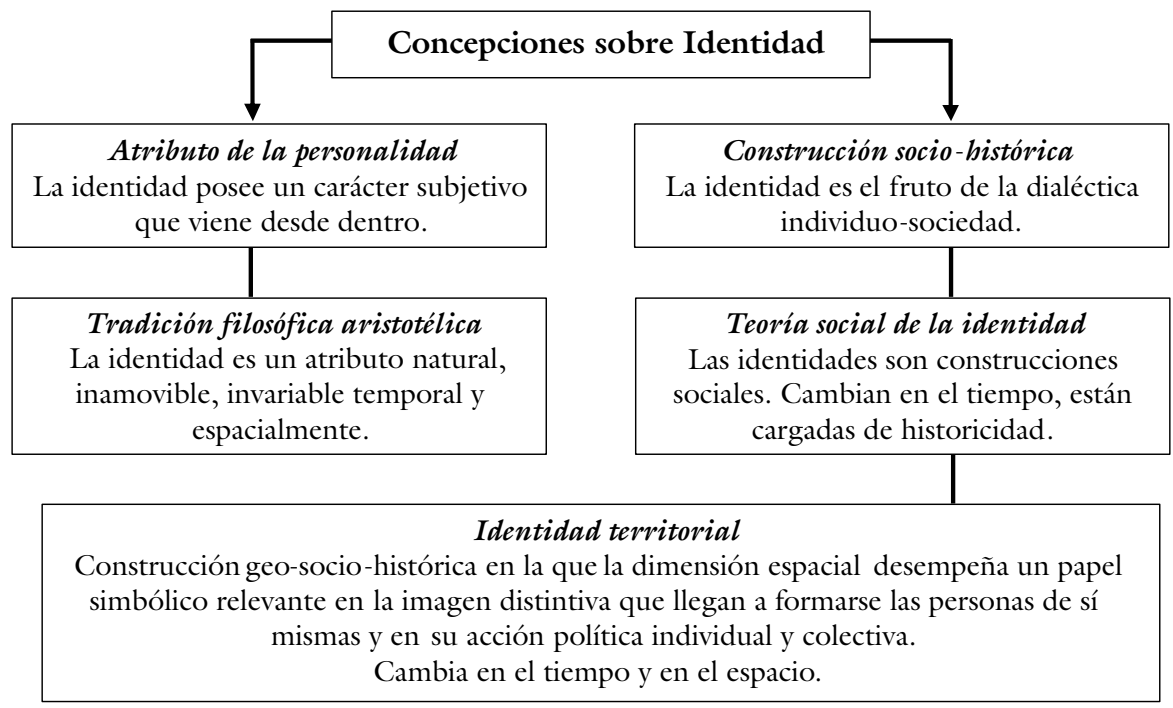

Fuente: elaborado a partir de Giménez (1997, 1999), Molina (2011) y Blanco et al. (2014).

\section{Territorialidades en la ciudad- región Eje Cafetero}

\section{Aspectos metodológicos}

El estudio se apoyó en la técnica cualitativa de la entrevista semiestructurada como una forma adecuada de acercamiento a los relatos verbales de los actores sociales de la ciudad-región, para buscar en ellos una visión y una descripción de los aspectos que evidenciaran la presencia de identidad territorial en la población. En consecuencia, el protocolo de entrevista se centró en aspectos como el significado que tiene para los actores la formación espacial ciudad-región Eje Cafetero, las formas de interacción que observan las poblaciones de sus municipios, los elementos de cohesión territorial que logran ser identificados y la imagen de futuro de la ciudad-región.

Se definió al actor social a partir de la idea de acción, como aquel que posee una historia y un discurso que orientan su práctica y dispone de los medios para actuar en correspondencia, a quien es posible atribuirle responsabilidad por los resultados de esas decisiones y/o actuaciones, una unidad de decisión-acción responsable (García, 2007), motivado por intereses particulares pero que igual asume compromisos con una visión colectiva de su territorio fundada en relaciones solidarias y de cooperación. 
Desde esa premisa, y partiendo de su esfera de actuación, se identificaron como actores sociales en la ciudad-región los empresarios locales, que sustentan las relaciones comerciales y los encadenamientos productivos; las organizaciones gremiales, que promueven alianzas productivas y proyectos público-privados; los investigadores y directivos de universidades, que impulsan alianzas académicas y proyectos público-privados; y los líderes políticos y funcionarios públicos, que poseen capacidad de gestión para consolidar los procesos de asociatividad territorial. Se consideró que en ellos se combinan capacidad y dominio para actuar de manera estratégica conforme a sus decisiones, en pro de intereses individuales y colectivos.

Por medio de un muestreo selectivo o intencional, que significó la revisión del cumplimiento del perfil definido y la disponibilidad de la persona para conceder la entrevista, y teniendo en cuenta que la selección de los entrevistados no respondía a la necesidad de generar una muestra representativa, sino más bien a sus posibilidades de ofrecer información profunda y detallada sobre el asunto de interés para la investigación, se realizaron 26 entrevistas que incluyeron actores de todos los municipios de la ciudad-región. ${ }^{3}$ El tamaño de la muestra se consideró apropiado bajo el criterio de saturación, que se alcanza cuando se ha escuchado ya una cierta diversidad de ideas y las entrevistas adicionales no ofrecen nuevos elementos (Martínez, 2012).
Para el tratamiento de la información se partió de entender que, como forma de conocimiento, la entrevista es una herramienta de carácter comunicativo que se propone captar significados que no son hechos puros o simples, en tanto están mediados por la construcción que hacen las distintas personas con base en su experiencia. Entonces, siguiendo un enfoque narrativo (Merlinsky, 2006), además de los contenidos producto del diálogo propiciado, se prestó atención a la secuencia de los hechos que se narraron y la intención y justificación de las acciones, se entrelazaron los relatos buscando temas comunes y posibles generalizaciones, y se establecieron relaciones entre los hechos interpretados por los actores y el pasado regional reciente. De esa manera, las entrevistas no fueron leídas en forma individual, ni en modo lineal.

\section{La identidad territorial desde la perspectiva de los actores}

La ciudad-región hace parte de lo que se conoce como el Eje Cafetero del centro occidente colombiano, evocado por sus habitantes como una región histórica, cuyos rasgos característicos actúan como repertorios comunes de orgullo. Este nombre delata una condición necesaria, el café como marco cultural de una construcción social y espacial que deriva de una actividad agrícola que aparece en el escenario histórico de su espacio geográfico
3 El trabajo de campo favoreció la interacción con siete integrantes de la élite empresarial regional, seis académicos $y / o$ directivos universitarios, cinco funcionarios de las áreas de planeación y ordenamiento territorial de los gobiernos locales, cuatro lideres politicos de los municipios y cuatro activistas cívicos.

territarias 42

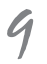


${ }^{4}$ Hoy el corazón de la actividad cafetera se desplazó al sur del pais. De acuerdo con el censo nacional agropecuario realizado en 2014 por el Departamento Administrativo Nacional de Estadisticas (DANE) (2014), en conjunto, en los departamentos de Huila, Cauca y Tolima se produce el $35.8 \%$ del café pergamino seco colombiano, en tanto que en los tres departamentos del Eje Cafetero solo se produce el $17 \%$.

\section{territarias 42}

a partir de los procesos de colonización interna en el siglo XIX.

Se trata de una región que tradicionalmente se refiere conteniendo tres departamentos, Caldas, Quindío y Risaralda, que en conjunto constituyeron hasta 1966 uno solo, el Gran Caldas (figura 2). El nombre Eje Cafetero tiene un origen aún poco claro; sin embargo, con este se evoca una actividad agrícola de gran significado en la historia económica, social y cultural de estos departamentos, a lo que se suma el hecho de que en un momento importante de esa historia la región fue el corazón de la actividad cafetera de Colombia. ${ }^{4}$

Como lo ilustran Arias y Bolivar (2006), el poblamiento del Eje Cafetero tuvo lugar en el contexto particular de colonización y redistribución del espacio, característico de la reorganización productiva del país frente a los avatares de la economía mundial del siglo XIX y la

Figura 2. Región Eje Cafetero y la ciudad-región

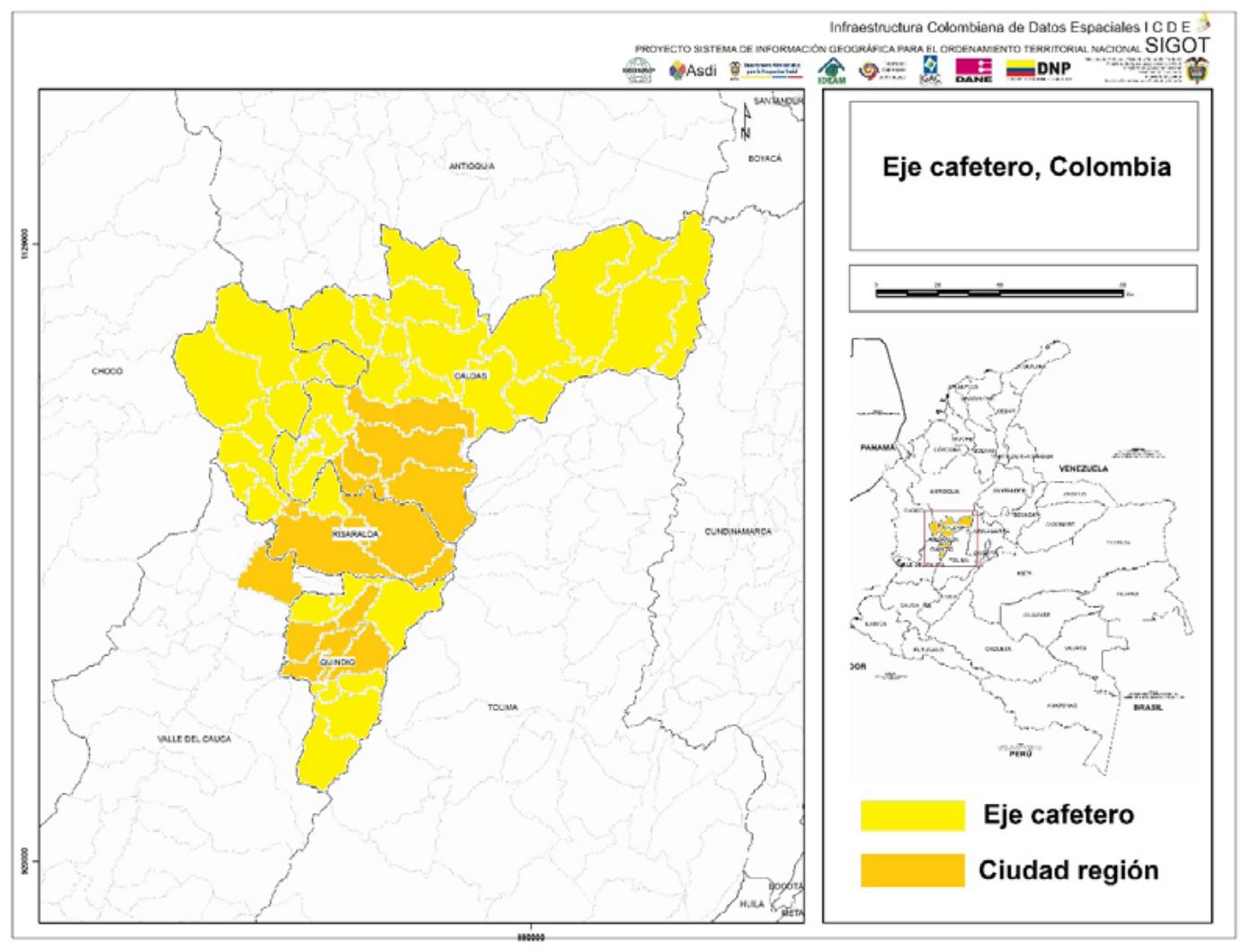

Fuente: elaboración propia. 
consecuente búsqueda de nuevos productos por medio de los cuales insertarse a la economía mundial. En ese contexto, el incremento y el progresivo establecimiento de la caficultura como actividad productiva central y de exportación se presentaron en lo que se considera una segunda etapa de colonización; es decir, después de que las familias pobres de colonos abrieron la frontera y mejoraron el terreno (la colonización pionera, 1842 y 1894), llegaron comerciantes y empresarios de ciudades establecidas que, animados por la rentabilidad que ofrecía esta actividad agrícola de exportación, buscaron la titulación de tierras con fines múltiples: dividir, vender, arrendar y participar en el cultivo y la comercialización del café (la colonización empresarial, 1894 y 1920).

En relación con ello, para algunos autores en la construcción y representación de una identidad colectiva en el Eje Cafetero ha sido central la narración que se ha hecho de la colonización, atada a este carácter cafetero de la región. Así, de acuerdo con Arias y Bolivar (2006), la construcción de esta memoria colonizadora es uno de los fundamentos de la identidad colectiva que se teje en el Eje Cafetero. La colonización de estos espacios ha sido vista como una empresa de dimensiones épicas, una epopeya, de la que nació una sociedad especial.

En el mismo sentido, Betancourt (2008) argumenta que en los primeros escritores de la historia local fue recurrente la apelación a un mito: la colonización antioqueña; de lo cual han pervivido una serie de imágenes entorno a su idealización y de estereotipos que se forjan desde allí sobre lo antioqueño, lo paisa. De esa manera, se exaltó un modo de ser, al que se concibió como la base de los progresos rápidos que hicieron de los núcleos urbanos como Manizales, Pereira y Armenia. Una visión que durante los años es reproducida en la población mediante distintas expresiones culturales. ${ }^{5}$

Algo que igual se observa en elementos simbólicos locales, como los himnos municipales que incorporan frases alusivas a las raíces antioqueñas de varios de los municipios. Es el caso del himno a Circasia, que en su segunda estrofa narra: "Por los riscos, los valles y prados, los abuelos portando la paz, nos trajeron principios sagrados, desde Antioquia en épica audaz"; por su parte, el alusivo a La Tebaida afirma que: "Somos arrieros de Antioquia, que ganamos la batalla, cuando fundamos un pueblo, para llamarlo tebaida"; finalmente, el himno a Santa Rosa de Cabal, en su segunda estrofa, habla de una ciudad "Reclinada con mágico hechizo en las faldas del ande antioqueño".

En la dinámica de interacción con los actores sociales de la ciudad-región, se observó que abundan los planteamientos que acuden al café y la colonización antioqueña como símbolos de definición del nosotros, lo que se complementa con discursos que atribuyen al cultivo una importancia sustancial para entender los
${ }^{5}$ Es el caso de algunas canciones emblemáticas del folclor local, como el Bambuco "La Ruana”, en el que Luis Carlos Gonzálezrefiere de manera amplia las raices quimbaya y paisa de la población. 
- El Paisaje cultural cafetero está conformado por zonas cafeteras de los departamentos de Caldas, Quindio, Risaralda y Valle del Cauca (47 municipios en el área principal y 4 en su área de amortiguamiento), ubicadas en las estribaciones Central y Occidental de la cordillera de los Andes. El 25 de junio de 2011 el Comité de Patrimonio Mundial de la Organización de las Naciones Unidas para la Educación, la Ciencia y la Cultura (Unesco) inscribió el Paisaje Cultural Cafetero en la Lista de Patrimonio Mundial.

\section{tersitarias 42}

repertorios culturales que marcan el destino de la región. De esa manera, se destaca como representativo de la vida de la región la cultura del café, en la que se amalgaman elementos del pasado y el presente, un pasado que se concibe vinculado al proceso colonizador y de implantación de esa actividad agrícola, cuya influencia histórica ha sido determinante y demanda esfuerzos colectivos para proyectarla en el tiempo, los cuales se vienen desplegando especialmente por medio de la conservación del Paisaje cultural cafetero. ${ }^{6}$

En esa revisión de los aspectos representativos de la región, y en una clara alusión a que ella es la gente que la habita, varios de los actores destacaron como aspectos característicos de su población la amabilidad, creatividad, laboriosidad, emprendimiento, aspectos que se considera están fuertemente relacionados con la influencia histórica de los paisas o antioquenos, gente trabajadora y emprendedora que es capaz de sobrevivir en medio de las dificultades.

Sin embargo, en las nuevas elaboraciones sobre el pasado regional se percibe la necesidad y la intensión de agregar matices a las imágenes de identificación regional. De manera concreta, las más recientes investigaciones históricas (Betancourt, 2008; Tobasura, 2008; López \& Correa, 2012 ) ponen en cuestión la narrativa sobre la que se ha centrado la colonización, afincada en una idea excluyente que concibe el Eje Cafetero como un fenómeno socioespacial vinculado en forma predominante, sino de manera exclusiva, a la colonización antioqueña.

De manera similar, las construcciones mentales del Eje Cafetero que elaboran los actores sociales, con mayor fuerza en aquellos de los municipios del Quindío, contribuyen a renovar los marcos de reconocimiento e identificación de la región. Construcciones a partir de las cuales se define a los habitantes de esta parte del país como una mezcla de cultura paisa y caucana, que tiene entre sus expresiones una población emprendedora, con arraigo fuerte a la tierra, pero con visión de mundo.

Esas lecturas que parten del reconocimiento de la presencia de un fenómeno más complejo y de carácter multicultural, en el proceso de conformación del Eje Cafetero en el siglo XIX, identifican una mayor influencia de la cultura paisa en Manizales y sus municipios cercanos, en tanto que en el Quindío se ha dado una mayor influencia caucana y cundiboyacense; y advierten sobre la presencia, en un departamento como el Quindío, de una mezcla de culturas (paisa, caucana, boyacense, cundinamarquesa, tolimense), dadas las poblaciones que han hecho presencia en la región.

De acuerdo con Tobasura (2008), en los primeros decenios del siglo Xx los productores de café tuvieron como práctica el reclutamiento de personal de las tierras altas de Boyacá, lo cual propició un movimiento migratorio de trabajadores desde estas zonas y dio origen a lo que 
más tarde sería la colonización boyacense y cundinamarquesa hacia la parte fría de la cordillera central, principalmente de municipios de Caldas. Sin embargo, esa movilización ha sido poco estudiada, un vacío que trata de llenar el autor a partir de relatos personales, que le permiten hacer un rastreo del proceso migratorio y colonizador cundiboyacense en el Viejo Caldas y Tolima.

El crecimiento demográfico, las escasas posibilidades de empleo y el empobrecimiento progresivo de la población se convirtieron en los factores que empujaron a los boyacenses a estas tierras. La violencia política de los años treinta y cincuenta del siglo Xx fue igualmente determinante. El desarrollo productivo y comercial fundado en el café facilitó el proceso de integración de las poblaciones receptora y migrante; los matrimonios de muchachas caldenses y trabajadores boyacenses, después de superada cierta "distancia social" inicial, fueron muy frecuentes en los años cincuenta.

Tobasura (2008) destaca como legados de la colonización boyacense el amor por el trabajo, la capacidad de sacrificio, la tenacidad, la ambición (a veces desmedida), la sumisión, la gratitud y el apego al dinero. A diferencia de la población de influencia paisa, los boyacenses no se han hecho notar; por ello, la colonización de los boyacenses en Caldas ha sido denominada como una colonización silenciosa.

Pero la multiculturalidad en la que se asientan el Eje Cafetero y la ciudad tiene raíces históricas más profundas, producto de una clara influencia precolombina. Si bien en los primeros trabajos de historia regional tiene muy poca importancia el pasado precolombino en la tarea de comprender la construcción socio-cultural de este territorio, al considerar que los grupos primitivos desaparecieron en la Colonia y el proceso colonizador fue realizado sin sangre india, en las nuevas lecturas de esa historia se invoca al pasado indígena para entender el juego de producción y negociación de identidades (Betancourt, 2008; Arias \& Bolivar, 2006). Ello está también contenido en el discurso de distintos actores sociales, que destacan la laboriosidad de la población como una herencia cultural que les viene por doble vía, tanto de los colonos antioqueños como de los indígenas quimbayas, y consideran que la imagen de su pasado Quimbaya refuerza y legitima unos rasgos que sustentan la identidad perseguida o pretendida en el presente.

Se evidencia entonces que, al igual que en las nuevas elaboraciones académicas sobre el pasado regional del Eje Cafetero, en las construcciones mentales de los actores sociales de la ciudad-región se reconoce la pertinencia y necesidad de agregar nuevos matices a las imágenes de identificación regional; de manera que si bien uno de los fundamentos de la identidad colectiva está ampliamente vinculado a los procesos de colonización de los que hicieron parte poblaciones nacionales de origen diverso, igual han sido relevantes el pasado indígena y otros fenómenos territarias 42 
contemporáneos, como las migraciones hacia algunos municipios de la ciudadregión afectados por eventos catastróficos (erupción del Volcán Nevado del Ruiz en 1985, sismo de 1999).

La homogeneidad no se presenta como la característica primaria del Eje Cafetero y su ciudad-región. La heterogeneidad con la que se edifica este territorio procede de su historia más lejana, cuando se construyeron pueblos en un choque de colores y razas: indígenas, negros, mestizos, caucanos, antioqueños, tolimenses, cundiboyacenses, entre otros, que cimentaron las bases de una población excepcional por su diversidad. Una diversidad que se asume como un valor de orgullo y calidad humana, esta última expresada en la amabilidad, calidez, solidaridad, creatividad, laboriosidad y emprendimiento, entre otras características que se resaltan de su gente.

Otro de los símbolos de definición del nosotros en los actores de la ciudadregión, tiene que ver con la cultura que se ha desarrollado alrededor de la producción del Café. El café se erige como centro de gran parte de las evocaciones que hacen de la región, tanto aquellas ancladas al pasado, como las que describen la condición presente o proyectan un destino común. Los actores sociales que participan de los procesos de la ciudadregión son insistentes en señalar que lo que hace diferente a esta región de otras del país tiene que ver con la cultura del café, y se define como característico de la vida regional su impronta cafetera
Una imagen distintiva que se añora conservar a futuro. Si bien las actividades como turismo, comercio, agroindustria, educación y cultura son algunas de las vocaciones regionales con las que los actores sociales de la ciudad-región proyectan el futuro regional; en ese ejercicio prospectivo está igualmente presente una expectativa de sostenibilidad de las tradiciones y potencialidades locales, que se expresan en un deseo repetido de conservación del paisaje cultural cafetero y la planeación de un desarrollo sustentado en condiciones endógenas.

De esta manera, si se observa desde los actores sociales, el café aparece como uno de los lugares comunes de la ciudad-región. La producción del grano y la cultura que se asocia con esta, hacen presencia constante en las imágenes a las que acuden dichos actores para entender la región. La cultura del café es una nostalgia que se renueva al momento de definir el 'nosotros', y el café se convierte en un referente de identidad para los pobladores de la ciudad-región.

Ahora, si finalmente el vínculo territorial tiene que ver con la construcción de un afecto personal y colectivo por el espacio habitado y todo lo que hay en él, como construcciones, paisajes, monumentos, calles, vegetación; en el caso de la ciudad-región esto se evidencia por medio del aprecio referido por los actores por ese paisaje natural que rodea $y$ envuelve a sus ciudades, el cual, además de ofrecer la posibilidad de disfrutar de las 
distintas tonalidades del verde, acoge una biodiversidad que destaca en los ámbitos nacional e internacional.

Al hablar de los aspectos que identifican la región y despiertan apego, los actores subrayan en forma repetida los elementos naturales; aquellos que los hacen sentir disfrutando de un mismo paisaje, no importa que se esté en espacios de Caldas, Risaralda o Quindío. De la misma manera, se afirma que un aspecto diferenciador de la región es el hecho de contar con una gran riqueza natural y una notable biodiversidad, la misma que resulta especialmente atractiva para los visitantes.

En el mismo sentido, las sensaciones primarias que emergen de la región se relacionan con el verde, la tierra, el agua, los ríos. Se sueña con una región que conserva su verde, cuando se pregunta por la imagen futura que tienen de su región, son recurrentes las referencias relacionadas con la riqueza natural y el deseo de conservación. Aquí algunas expresiones frecuentes: región verde, región de paisaje, equilibrio social y ambiental, una gran ciudad-región verde, en armonía con la naturaleza, región que protege el medio ambiente.

En la revisión de ese vínculo territorial se exploró la relación que se percibe con la ciudad-región Eje Cafetero y se evidenció que en las imágenes mentales de los actores existe la ciudad-región; ella se reconoce como realidad socioespacial y destaca como un elemento diferenciador en el entorno nacional, que plantea retos a la planificación y el ordenamiento territorial. Sin embargo, se entiende de manera diversa, hay quienes la asumen como la articulación de Manizales, Armenia, Pereira, considerando en algunos casos sus áreas de influencia; otros como la integración de la zona centro-sur de Caldas y el Área metropolitana Centro Occidente, incluyendo los municipios de Santa Rosa de Cabal y Cartago; en tanto algunos prefieren hablar en plural, destacando la presencia de varias ciudades región en el Eje Cafetero.

A la ciudad-región se le identifica como un fenómeno socioespacial en marcha, entendiendo en algunos casos que pueblos tan cercanos, que están cada vez más articulados, no pueden seguir trabajando de manera distante y la asociación de estos es un proceso que tarde o temprano se consolidará; en otros que la formalización de la ciudad-región constituye una necesidad estratégica. De la misma manera que el Eje Cafetero se erige verde en el imaginario de sus habitantes, la ciudadregión, en sus distintas conformaciones, aparece como un referente espacial y lo urbano se hace central en el repertorio de identificación del territorio, en tanto lo rural aparece como paisaje, como telón de fondo. De alguna manera, esto da sentido a los discursos de desarrollo que centran interés especial en los centros urbanos y en la infraestructura de las ciudades.

La vida de las ciudades capitales marca con fuerza el imaginario de ciudad-región, 
ya que proporciona nodos de conexión y movimiento que la definen y la hacen comprensible para los actores sociales. El vínculo más inmediato de los municipios es con su ciudad capital, la que aparece de manera repetida como una de las unidades urbanas con la que se establecen relaciones de orden económico (laboral, comercial), social y/o familiar, y por medio de ella se concreta la vinculación a la ciudad región.

No obstante, la presencia que en el imaginario de los actores tiene la ciudad región en sus distintas configuraciones, resulta claro que la región Eje Cafetero se constituye en el referente socio-espacial con el que más se identifican dichos actores. Al tiempo que el municipio de residencia es el Eje Cafetero, el lugar que despierta un mayor apego en los actores y se utiliza de manera recurrente para demarcar espacialmente el territorio al que consideran pertenecer. Aún más, existe una sensación de reconocimiento por parte de 'los otros', a partir de la condición de habitantes del Eje Cafetero “[...] no nos ven ni como Caldas, ni Quindío, ni Risaralda, nos ven como Eje Cafetero [...]", plantea alguno de los entrevistados.

El Eje Cafetero se erige como referente primario de pertenencia, y desde ella se habla de quiénes sí y quiénes no hacen parte de la ciudad-región. Esta región, repetida en el imaginario colectivo como noción primaria de lo que fuera el Gran Caldas, sigue viva en la evidencia de los mapas producto de las elaboraciones mentales de los actores sociales que, de manera sostenida, acuden a ella como espacio de referencia tradicional. Pero en los mapas imaginados de los actores, ese Eje Cafetero amplía sus fronteras y se extiende más allá de sus límites clásicos, hacia sus alrededores. Emergen municipios y lugares cercanos que se vinculan a ella por razones de experiencia espacial (municipios vecinos del Norte del Valle y del noroccidente del Tolima), ampliándose en bordes frágiles que se explican por los movimientos, las estancias temporales, la residencia de la familia, los negocios, los recuerdos, los proyectos de vida, la identificación con el vecino o la imaginación creadora.

Ese mayor vínculo de los actores con un espacio más amplio como el Eje Cafetero es consistente con la idea de Borja (2005), cuando advierte que una ciudad-región puede ser más una forma espacial que un territorio, dadas dificultades de cohesión social, identidad y gobernabilidad; por lo cual, el desafío está en desarrollar estrategias que configuren el espacio de la ciudad-región como territorio, y un punto de partida es concretar su formalización en función de las formas asociativas planteadas por la Ley Orgánica de Ordenamiento Territorial (LOOT).

Diversos aspectos favorecen ese propósito asociativo, de acuerdo con la percepción que tienen los actores de la dinámica de integración existente en el Eje Cafetero y la ciudad-región. Entre ellos, se destacan el trabajo cooperativo de las universidades públicas asentadas en las tres capitales, por medio de organizaciones como Sueje; los 
intereses ambientales compartidos, especialmente en el manejo de las cuencas; el desarrollo del turismo, mediante rutas y proyectos turísticos de nivel supramunicipal; la infraestructura vial y los elementos de identidad en torno al café y el paisaje cultural.

Un obstáculo a la integración, tradicionalmente esgrimido, es el de los odios derivados del proceso de escisión del antiguo Caldas en tres entidades departamentales. Como lo describen López y Correa (2012), luego de la Reforma Constitucional llevada a cabo en Colombia en el año de 1905, se dividió el mapa político administrativo del país en 33 entidades territoriales y se creó el departamento de Caldas, producto de la división de la zona suroccidental de Antioquia, erigiéndose Manizales como su capital y llegando a incorporar hacia 1912 un espacio geográfico que coincide con lo que acá se ha denominado Eje Cafetero.

Desde la creación del departamento de Caldas se dejaron sentir ciertos inconformismos políticos entre los grupos de élites de poblados vecinos como Pereira y Armenia que, paralelo a Manizales, habían logrado alcanzar un gran dinamismo económico en las primeras décadas del siglo $\mathrm{xx}$; por lo que, al cabo de unas décadas, se exacerbó una gran rivalidad por asuntos de inversión presupuestal, autonomía y descentralización.

Según López y Correa (2012), las rencillas y los reclamos públicos entre los dirigentes de las tres principales ciudades:
Manizales, Pereira y Armenia, fueron en aumento, y si en las décadas de 1920 y 1930 se materializaron en diferencias por la administración de los ferrocarriles, la legitimidad de la capital departamental y la distribución fiscal, entre otras, en la década de 1940 estas se cristalizaron en fuertes disputas partidistas. Posteriormente, las disputas se orientaron en una lucha por la centralización/descentralización administrativa, en la cual los gremios económicos emergieron como los principales actores urbanos. Disputas que tuvieron su máxima expresión entre 1966 y 1967, cuando se presenta la división de Caldas y la creación de los departamentos de Quindío y Risaralda como nuevas entidades administrativas autónomas.

En la memoria de muchos de los actores sociales está presente este momento histórico y para ellos son claras las razones de la escisión, relacionadas en lo fundamental con el centralismo político y administrativo practicado en ese entonces por la capital Manizales; sin embargo, esto no aparece en los imaginarios de los actores como fuente de odios regionales que se conservan y obstaculizan la integración. Más bien, ese papel lo están asumiendo las arrogancias locales que promueven y son leídas como nuevas posturas centralistas.

Los actores de los municipios de Caldas, distintos a Manizales, coinciden en señalar que las relaciones de la capital con su municipio son planteadas en términos ampliamente jerárquicos, con clara imposición unilateral de condiciones. Se territarias 42 
hace lectura de una sociedad manizaleña cerrada, que da la sensación de pretender mantenerse aislada y se afirma que Manizales no puede seguir teniendo una mirada autárquica en un contexto global en el que las regiones comienzan a ser muy importantes.

En el mismo sentido, algunos de los actores residentes en los municipios del Quindío, distintos a la capital, perciben que una de las mayores dificultades para la integración, especialmente en lo que tiene que ver con la consolidación de su área metropolitana, se relaciona con la posición centralista que observan en la dirigencia de Armenia, llegando a considerar que casi todos los municipios del departamento del Quindío dependen de lo que se diga en Armenia, condición en la cual se ve reflejada una situación muy similar a la que se vivió con Manizales como capital del antiguo Gran Caldas.

En lo referido a Pereira, el trabajo de campo permitió evidenciar el malestar que en el ámbito regional genera su autodenominación como "Pereira, capital del Eje", lo cual constituye el propósito central del plan de desarrollo 2016-2019. Según se plantea en las páginas introductorias de dicho plan (Alcaldía de Pereira, 2016), es el fruto de una construcción colectiva en la que participaron organizaciones no gubernamentales, instituciones educativas, comunidades de comunas y corregimientos, agremiaciones empresariales, universidades, sector privado, ciudadanos territarias 42 18 funcionarios de la Administración Municipal, asesores y colectivos sociales, entre otros; lo que hace suponer un consenso de diferentes fuerzas locales para la denominación contenida en el nombre del plan.

El sueño de ciudad región está presente en la variedad de discursos institucionales del desarrollo en el Eje Cafetero; no obstante, desde los múltiples anhelos de formalización de esa figura espacial no se ha logrado unificar el nosotros. Cada capital se muestra impulsada a autodefinirse como la ciudad-región, a la cual se insertan otras ciudades del sistema urbano del Eje Cafetero, mediante un proceso generalmente mediado por las restantes capitales y con la presencia de relaciones de orden estrictamente jerárquico.

En los más recientes ejercicios de planeación, Armenia (Alcaldía de Armenia, 2016) y Cartago (Alcaldía de Cartago, 2016) se asumen como la ciudad-región en su relación con los municipios circunvecinos. De manera similar, se considera que Manizales “...podrá concebirse como la ciudad-región de la subregión centro sur, pues es indudable su capacidad diferencial de ser centro de servicios y de crecimiento frente a las demás..." (Alcaldía de Manizales, 2016, p. 335 ) y se sugiere avanzar en un sistema de transporte que la integre de forma eficiente con las ciudades de Pereira, Armenia y Cartago. De otro lado, como se señaló, a Pereira (Alcaldía de Pereira, 2016) se le define como "la capital del Eje" y se identifican como referentes de integración de la región metropolitana 
(Santa Rosa, Dosquebradas, Pereira, La Virginia, Cartago) y el eje de integración cafetero (Manizales, Pereira, Armenia).

\section{Conclusiones}

Las experiencias del trabajo de campo evidenciaron una conciencia en la población según la cual el Eje Cafetero, y la ciudadregión como parte de ella, se erigen desde una perspectiva de multiculturalidad y se construyen mediante una práctica social y cotidiana que produce sentido social diverso. La interacción espacial entre sus municipios, referida en las entrevistas y evidenciada en otros trabajos (Gaviria, 2018), si bien de alguna forma ha aportado a la complejidad de esa diversidad, igual ha servido al desarrollo de solidaridades en torno a la tarea de consolidar la ciudad-región.

En el imaginario de los actores son observables ciertos rasgos caracterizados por su estabilidad y esencia, que hablan de la pertenencia territorial anclada en el pasado, pero que se renueva con los fenómenos actuales y se redefine a partir de estos. Se destaca la influencia cultural de los movimientos poblacionales mediatos (colonización antioqueña y caucana, migración cundiboyacense), y aún de los inmediatos (migraciones posteriores a eventos catastróficos), en el marco de una remembranza de los orígenes precolombinos. También se añora y se pretende conservar a futuro la cultura del café como imagen distintiva, pero en un claro compromiso con el medio ambiente y la defensa de la riqueza natural regional y es preponderante la imagen urbana de la región, llegándose a destacar su tejido urbano como una de las más sobresalientes diferencias frente a sus similares, pero se evoca rodeada del verde de sus paisajes naturales.

Pese a las diferencias en las perspectivas que se imprimen en cada actor, lo cual guarda cierta relación con la localidad a la que él pertenece, es posible extraer de su discurso la existencia de un 'nosotros', especialmente cuando se evoca al Eje Cafetero. En el imaginario colectivo de los actores se evocan rasgos del ser de la región, concebidos además como un motivo de orgullo y como un recurso para enfrentar el futuro: la gente pujante, amable, cálida, solidaria, creativa, emprendedora; el patrimonio cultural y material, heredado y construido alrededor de la actividad cafetera; el crecimiento de las ciudades y el paisaje que las arropa; y las características del espacio geográfico, su belleza natural y riqueza biodiversa hacen parte de los atributos de este territorio en construcción que, como se señaló, mantiene cierta memoria de su pasado y se redefine a partir de los hechos contemporáneos.

A partir de lo que significa el Eje Cafetero para sus habitantes, la ciudadregión puede llegar a configurarse como territorio, claramente reconocible por sus habitantes y simbólicamente construido tanto de repertorios históricos como de territarios 42

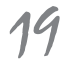




\section{territarios 42}

nuevas formas de identificación. La idea de hablar de la ciudad-región como territorio para el desarrollo cobra importancia en el discurso de los actores, que la ven en sus imágenes de futuro como un proyecto que debe consolidarse, en atención a las realidades socio-espaciales presentes y la necesidad estratégica de articular fuerzas y potencialidades locales, en tanto de otra forma, como se sugirió en algunas entrevistas, Medellín y Cali absorben a sus principales centros urbanos por separado.

Como se ha argumentado, el territorio se estructura y organiza a partir de las relaciones que establecen los seres humanos entre ellos y con el espacio habitado, el territorio se configura a partir de relaciones sociales, y una de las formas de concreción de esas relaciones es por medio de los fenómenos de movilidad y comunicación, manifiestos en la circulación de personas y el intercambio de información. La ciudad-región aún resulta ser más una formación espacial que un territorio y su formalización como esquema asociativo de entidades municipales no es garantía de territorialización, es apenas la respuesta a una necesidad derivada de las dinámicas de desarrollo presentes. Su constitución como territorio sigue siendo entonces un gran desafío; no obstante, la interacción espacial existente, la misma que puede resultar fortalecida con el proceso asociativo, es fuente de relaciones sociales a partir de las cuales se continúan alimentando solidaridades y se fortalecen los apegos por el espacio, lo que insinúa un proceso de configuración territorial en marcha.

Una estrategia orientada al fortalecimiento de la identidad territorial y el apego de la población por la ciudad región requerirá apelar, entre otros referentes fundamentales, a la cultura del café, que fue identificada durante el trabajo de campo como símbolo esencial en la definición del 'nosotros', y a elementos de diferenciación y fuente de oportunidades, como el tejido urbano rodeado de verde que configura la ciudad región. Lo primero plantea como reto definir la manera de preservar esos valores tradicionales que han servido al fortalecimiento del tejido social y cultural del Eje Cafetero y la ciudad-región, siempre reconociendo que se imponen nuevas alternativas de generación de riqueza y resulta inevitable el desarrollo científico y técnico. El Paisaje cultural cafetero, producido por medio del esfuerzo colectivo de varias generaciones de agricultores que se sirvieron de los saberes transmitidos y acogieron prácticas innovadoras para la gestión de los recursos del medio natural, es en sí mismo evidencia de la posibilidad de combinar tradición y tecnología para garantizar la calidad y sostenibilidad de un producto.

Lo segundo parte de reconocer la preponderancia de una imagen urbana en la identificación que se hace del Eje Cafetero, llegándose a destacar su tejido urbano rodeado del verde de los paisajes naturales como una de las más sobresalientes 
diferencias frente a otras regiones del país. De esa manera, la ciudad región puede mostrarse como un elemento de identidad y reconocimiento en el ámbito nacional, que además debe ser valorada por las oportunidades que ofrece para la gestión ambiental, la eficiencia en el uso de los recursos públicos y el aprovechamiento de ventajas de aglomeración en la escala regional, entre otras.

\section{Referencias}

Alcaldía de Armenia (2016). Plan de desarrollo del municipio de Armenia 20162019 "Sigamos adelante". Recuperado de http://planeacionarmenia.gov. $\mathrm{co} /$ plan-de-desarrollo-sigamos-adelante-2016-2019/

Alcaldía de Cartago (2016). Plan de desarrollo "Todos por Cartago", periodo 2016-2019. Recuperado de http://www.siipe.co/wp-content/ uploads/2014/08/Plan-Cartago.pdf

Alcaldía de Manizales (2016). Plan de desarrollo 2016-2019, Manizales más oportunidades. Recuperado de http:// www.manizales.gov.co/Recursos Alcal dia/201605021636516132.pdf

Alcaldía de Pereira (2016). Plan de desarrollo municipal 2016-2019 "Pereira, capital del eje”. Recuperado de http:// www.pereira.gov.co/Transparencia/ PlaneacionGestionyControl/Plan\%20 de\%20Desarrollo\%202016\%20-\%20 2019.pdf
Amtmann, C. (1997). Identidad regional y articulación de los actores sociales en procesos de desarrollo. Revista Austral de ciencias sociales, 1, 5-14.

Arias, J., \& Bolívar, Í. (2006). El cultivo de la identidad natural. Paisaje, cultura y turismo en Montenegro, Quindío. En Í. Bolívar (editora), Identidades culturales y formación del estado en Colombia: colonización, naturaleza y cultura (pp. 51-118). Bogotá: Ediciones Uniandes.

Betancourt, A. (2008). La construcción de una memoria regional: una mirada a la escritura de la historia en el Eje Cafetero. En A. Betancourt (editor), Policromias de una región Procesos históricos y construcción del pasado local en el Eje Cafetero (pp. 229-252). Pereira: Red de Universidades Públicas del Eje Cafetero - Alma Mater.

Blanco, J., Wulff, A., \& Basualdo, J. (2014). Estudio Identidad territorial. Informe final. Buenos Aires: Subsecretaría de Planificación Territorial de la Inversión Pública, Banco de Desarrollo de América Latina (CAF). Recuperado de https://www.mininterior.gov. ar/planificacion/pdf/Estudio-deidentidad-territorial-informe-finalseptiembre-de-2014.pdf. Mayo 4 de 2017.

Borja, J. (2005). La ciudad conquistada. Madrid: Alianza Editorial. Primera reimpresión.

Capel, H. (2016). Las ciencias sociales y el estudio del territorio. Biblio3W, Revista bibliográfica de geografía y ciencias territarias 42 


\section{territarias 42}

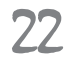

sociales, 21(149), 1-38. Recuperado de http://www.ub.edu/geocrit/b3w1149.pdf

Corporación Alma Mater, Carder, Corpocaldas, Cortolima, CRQ, CVC, Ministerio del medio ambiente (2002). Ecorregión Eje Cafetero: un territorio de oportunidades. Pereira: Corporación Alma Mater.

Cuervo, L. M. (2006). Globalización y territorio. Serie Gestión Pública, No 56, Santiago de Chile: ILPES.

DANE (2014). Censo Nacional Agropecuario 2014. Bogotá: DANE. Recuperado de: https://www.dane.gov.co/index.php/ estadisticas-por-tema/agropecuario/ censo-nacional-agropecuario-2014\#11

Dematteis, G. (1998). Suburbanización y periurbanización: ciudades anglosajonas y ciudades latinas. En F. Monclus (editor), La ciudad dispersa: suburbanización y nuevas periferias (pp. 17-33). Barcelona: Centre de Cultura Contemporánia de Barcelona.

Farias, A., Saquet, M., \& Alves, R. (2005). $\mathrm{O}$ territorio: diferentes abordagens e conceito-chave para a comprenensao da migracao. Revista Fax Ciência, 07(01), 11-26.

García, E. (2007). El concepto de actor. Reflexiones y propuestas para la ciencia política. Andamios. Revista de Investigación Social, 3(6), 199-216.

Gaviria, M. (2018). Redes y territorialidad en la Ciudad, región Eje Cafetero. Desenvolvimento, fronteras e ciudadanía, 2(1), 75-79.
Giménez, G. (1994). Apuntes para una teoría de la región y de la identidad regional. Estudios sobve las Culturas Contemporáneas, 7(18), 165-173.

Giménez, G. (1997). Materiales para una teoría de las identidades sociales. Frontera Norte, 9(18), 9-28.

Giménez, G. (1999). Territorio, cultura e identidades. La región sociocultural. Estudios sobre las Culturas Contemporáneas, 5(9), 25-57.

Giménez, G. (2005). Territorio e identidad. Breve introducción a la geografía cultural. Trayectorias, 7, (17), 8-24.

Haesbaert, R. (2011). El mito de la desterritorialización. Del "fin de los territorios" a la multiterritorialidad. México: Siglo XXI editores.

Haesbaert, R. (2013). Del mito de la desterritorialización a la multiterritorialidad. Cultura y representaciones sociales, $8(15), 9-42$.

Indovina, F. (2004). La ciudad difusa. En Á. Ramos (coordinador), Lo urbano en 20 autores contemporáneos (pp. 49-59). España: Universitat Politècnica de Catalunya.

López, J. \& Correa, J. (2012). Disputas por la centralización/descentralización administrativa en el Viejo Caldas, 1905-1966: los casos de Manizales y Pereira. Anuario Colombiano de Historia Social y de la Cultura, 39(2), 187-216.

Lopes Souza, M. (2009). "Território" da divergência (e da confusão): em torno das imprecisas fronteiras de um 
conceito fundamental. En M. Saquet, \& E. S. Sposito (organizadores), Territórios e territorialidades: teorias, processos e conflitos (pp.57-72), São Paulo: Expressão Popular - UNESP.

Martínez, C. (2012). El muestreo en investigación cualitativa. Principios básicos y algunas controversias. Ciência \& Saúde Coletiva, 17(3), 613-619.

Merlinsky, G. (2006). La Entrevista como Forma de Conocimiento y como Texto Negociado: Notas para una pedagogía de la investigación. Cinta Moebio 27, 248-255.

Molina, W. (2011). Identidad Regional en Magallanes, sus Expresiones Simbólicas y Territoriales. Magallania, 39(1), 59-69.

Monclús, F. (1998). Suburbanización y nuevas periferias: perspectivas geográficourbanísticas. En F. Monclus (editor), La ciudad dispersa: suburbanización y nuevas periferias (pp. 5-15). Barcelona: Centre de Cultura Contemporánia de Barcelona.

Monnet, J. (2013). El territorio reticular. En B. Nates (coordinadora), Enfoques $y$ métodos en estudios territoriales (pp. 137-167). Manizales: Universidad de Caldas.

Monnet, J. (1999). Globalización y territorializaciones 'areolar' y 'reticular': Los Ángelesy la Ciudad de México. Memorias del V Seminario Internacional de la Red Iberoamericana de Investigadores sobre Globalización y Territorio. Toluca,
México. Recuperado de http://halshs. archives-ouvertes.fr/halshs-00007796 Nates, B. (2011). Soportes teóricos y etnográficos sobre conceptos de territorio. Revista Co-berencia, 8(14), 209-229. Raffestin, C. (2011). Por una geografía del poder. Traducción y notas Yanga Villagómez Velázquez. México: El Colegio de Michoacan.

Saquet, M. (2007). As diferentes abordagens do território e a apreensão do movimento e da (i)materialidade. Geosul, $22(43), 55-76$.

Sánchez, J. (2001). La región y el enfoque regional en Geografía Económica. Boletín de la A.G.E., 32, 95-111.

Santos, M. (1994). O retorno do territorio. In M. Santos, M. Souza \& M. Silveira (Organizadores), Territorio, globalizacao e fragmentacao (pp. 15-25). Sao Paulo: Hucitec-Anpur.

Santos, M. (2000). La naturaleza del espacio. Técnica y tiempo. Razón y emoción. Barcelona: Ariel.

Schneider, S. \& Peyré, I. (2006). Territorio y enfoque territorial: de las referencias cognitivas a los aportes aplicados al análisis de los procesos sociales rurales. En M. Manzanal, G. Neiman \& M. Lattuada (organizadores), Desarrollo Rural. Organizaciones, Instituciones y Territorio (pp. 71-102). Buenos Aires: Ed. Ciccus.

Soja, E. (2008). Postmetrópolis: estudios criticos sobre las ciudades y las regiones. Madrid: Traficantes de Sueños. territorias 42

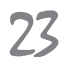


Storey, D. (2012). Territories. The claiming of space. Londres: Routledge.

Tobasura, I. (2008). Boyacenses y Cundinamarqueses en Caldas: Del quietismo social a la construcción de región. En A. Betancourt (editor), Policromias de una región Procesos históricos y construcción del pasado local en el Eje Cafetero (pp. 109-134). Pereira: Red de Universidades Públicas del Eje Cafetero - Alma Mater.

Vargas, G. (2012). Espacio y territorio en el análisis geográfico. Reflexiones, 91(1), 313-326. 